\section{Nail dystrophy due to diabetic neuropathy}

Nail changes may occur in diabetics in association with trophic changes or ischaemia. We describe a diabetic patient in whom fingernail dystrophy occurred as a result of a bilateral ulnar neuropathy.

\section{Case report}

A 72-year-old man presented in 1979 with a two-year history of changes affecting the nails of the ring and little fingers of both hands. During this time he had experienced numbness and tingling of these fingers and some difficulty in moving them. He had also had numbness and tingling of both feet for 17 years and difficulty in moving the right foot for one year. A known diabetic since 1962 with retinopathy and glaucoma, when seen he was taking glibenclamide $15 \mathrm{mg}$ daily, metformin $500 \mathrm{mg}$ twice daily, and acetazolamide $500 \mathrm{mg}$ daily.

Examination showed shortening, fragility, and yellow discolouration of

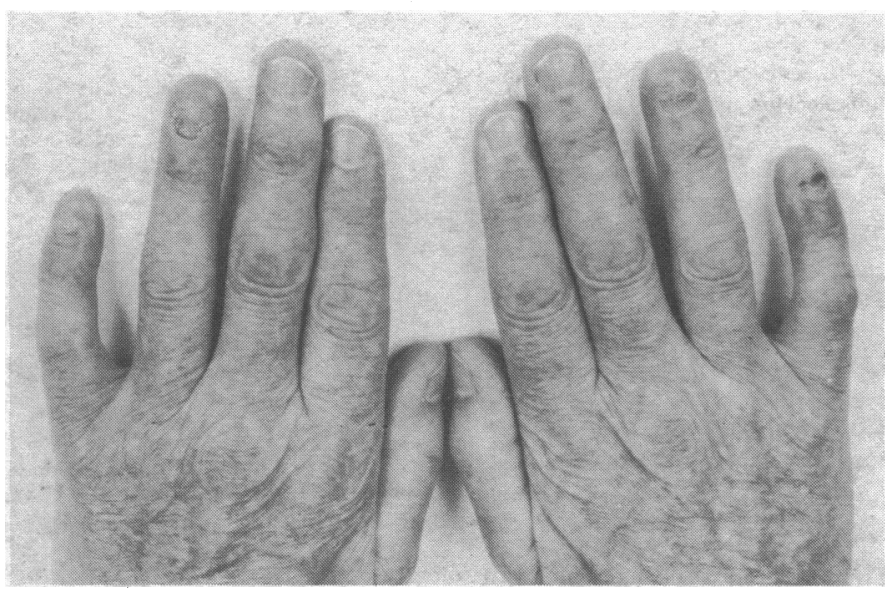

Fingernails, showing the distribution of nail dystrophy.

the nails of the ring and little fingers of both hands (figure). Neurological examination showed wasting of the interossei, decreased ability to adduct and abduct the fingers, right foot drop, decreased pinprick and light touch sensation over the ring and little fingers of both hands, decreased pinprick and light touch sensation up to the mid-shin level on both sides, absen vibration sensation over the ankles, and absent ankle jerks. Mycological examination of clippings from the affected fingernails gave negative results. It was concluded that he had a mononeuritis multiplex affecting the ulnar and right popliteal nerves and that the fingernail dystrophy was related to the ulnar neuropathy.

\section{Comment}

Nail changes may occur as a result of neurological lesions. Mitchell ${ }^{1}$ found that cerebral palsy with or without sensory loss caused decreased nail growth or nail dystrophy, or both, on the affected side. He subsequently reported on a patient in whom dystrophy of the nail of the little finger developed after an ulnar nerve "wound".2 A similar patient whose little fingernail became dystrophic after the cutaneous branch of the ulnar nerve to that finger was severed was described by Sharpey-Schafer. ${ }^{3}$ Some authors state that sensory loss alone does not cause decreased nail growth or nail dystrophy and that a motor weakness ${ }^{4}$ or some form of immobilisation ${ }^{5}$ is necessary. Our case does not contribute further to this problem as there were sensory and motor changes involving the affected digits. We have been unable to find any previous reports of nail dystrophy caused by a mononeuritis multiplex.

1 Mitchell SW. On the growth of nails as a prognostic indication in cerebral palsy. Am f Med Sci $1871 ; 61: 420-2$.

2 Mitchell SW. Injuries of nerves and their consequences. Philadelphia: Lippincott, 1872.

Sharpey-Schafer E. Observations on the relative rate of growth of the nails of the right and left hands respectively: on seasonal variations in the rate, and on the influence of nerve section upon it. Proc $R$ Soc Edinb 1930;51:8-13.
${ }^{4}$ Head $\mathrm{H}$, Sherren J. Changes in the nails associated with nerve injuries. Brain 1908;28:263-75.

5 Dawber R. The effect of immobilization on fingernail growth. Clin Exp Dermatol $1981 ; 6: 533-5$

(Accepted 26 February 1982)

Department of Dermatology, Bristol Royal Infirmary, Bristol BS2 8HW

R J MANN, MB, MRCP, senior registrar

J L BURTON, MD, FRCP, senior lecturer

\section{Paraquat ingestion with methaemoglobinaemia treated with methylene blue}

We describe a case of methaemoglobinaemia and haemolysis associated with ingestion of paraquat.

\section{Case report}

A 32-year-old horticultural worker presented to the casualty department having drunk a bottle of whisky, four pints of beer, and about three mouthfuls of Gramanol (10\% paraquat) in an episode of depression. Initially he refused all treatment, and even after 10 hours he agreed to take only $20 \mathrm{ml}$ Fuller's earth and magnesium sulphate solution by mouth. He had a sore throat, abdominal pain, nausea, and vomiting.

On examination about 10 hours after he had taken the paraquat he was drowsy and confused and had central cyanosis with a slate-grey complexion but was not dyspnoeic. He had periodic respiration. Spider naevi were present. Blood pressure was $130 / 90 \mathrm{~mm} \mathrm{Hg}$ with good peripheral perfusion, and the chest was clear. Chest radiography was normal, and his arterial blood looked blue-black despite an arterial oxygen pressure of $32 \mathrm{kPA}$ $(240 \mathrm{~mm} \mathrm{Hg})$ while receiving 81 oxygen/min by mask. Spectroscopy showed the presence of methaemoglobin. Although his serum creatinine concentrations and urine output were normal initially, haemodialysis through an arteriovenous shunt was started in case he had taken an unknown oxidising agent in addition to paraquat. Methylene blue $1 \mathrm{mg} / \mathrm{kg}$ was infused to reduce the methaemoglobin. The effect was dramatic: his colour reverted to normal, and he was more alert and co-operative. Oxygen was discontinued.

Six hours later we learnt that the paraquat concentration on admission had been $55 \mu \mathrm{g} / 1$ (12 hours after ingestion). This was below toxic concentrations. We also learnt that methaemoglobin had constituted $18.7 \%$ of total haemoglobin (that is, $3 \mathrm{~g} / \mathrm{dl}$ ) before methylene blue was given and $1.6 \%$ of total haemoglobin afterwards. A few Heinz bodies were seen During the next week he developed mild renal impairment and a cough with purulent sputum. Both resolved quickly. He then developed haemolysis, the haemoglobin concentration falling to $11.5 \mathrm{~g} / \mathrm{dl}$, with a reticulocytosis of $5 \%$. This too recovered. Glucose-6-phosphate dehydrogenase activity was normal. There was no permanent lung damage.

\section{Comment}

Analysis of Gramanol showed paraquat $10 \%$ and monolinuron, a dispersing agent that is not known to cause methaemoglobinaemia. There was no chlorate or nitrate. Paraquat is an electron acceptor, increasing oxidation of nicotinamide-adenine-dinucleotide phosphate. The reduced paraquat is then reoxidised to paraquat by oxygen with production of superoxide ions. ${ }^{1}$ These ions damage tissues and produce hydrogen peroxide, which can cause peroxidation of lipid cell membranes.

Theoretically it is possible that superoxide ions and hydrogen peroxide could oxidise haemoglobin to methaemoglobin, leading to oxidant-induced haemolysis. We have not found any published evidence for this or any evidence that alcohol potentiates the toxicity of paraquat. The apparent improvement in his drowsiness and confusion after methylene blue cannot be explained by a greater oxygen capacity in the blood, as the methaemoglobinaemia was not severe enough to reduce this capacity appreciably. The lung damage caused by paraquat takes several days to develop ${ }^{2-4}$ though may occur more quickly if a large amount is ingested..$^{5}$ Cyanosis within hours of ingestion of paraquat should therefore lead to the suspicion of methaemoglobinaemia. If this is confirmed, treatment with methylene blue may well be worth while. 